\title{
BMJ Open Primary care workforce and continuous medical education in China: lessons to learn from a nationwide cross- sectional survey
}

\author{
William C W Wong, ${ }^{1}$ ShanZhu Zhu, ${ }^{2}$ Jason J Ong, ${ }^{3}$ MingHui Peng, ${ }^{2}$ \\ Cindy L K Lam, ${ }^{1}$ Michael R Kidd, ${ }^{4}$ Martin Roland, ${ }^{5}$ SunFang Jiang ${ }^{2}$
}

To cite: Wong WCW, Zhu SZ, Ong JJ, et al. Primary care workforce and continuous medical education in China: lessons to learn from a nationwide crosssectional survey. BMJ Open 2017;7:e015145. doi:10.1136/ bmjopen-2016-015145

- Prepublication history and additional material are available. To view these files, please visit the journal online (http://dx.doi. org/10.1136/bmjopen-2016015145).

WCWW and SZZ contributed equally.

Received 28 November 2016 Revised 27 May 2017 Accepted 12 June 2017

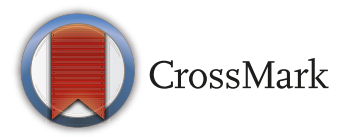

${ }^{1}$ Department of Family Medicine and Primary Care, University of Hong Kong, Hong Kong, China ${ }^{2}$ General Practice Department, Zhongshan Hospital, Fudan University, Shanghai, China ${ }^{3}$ Central Clinical School, Monash University, Melbourne, Australia ${ }^{4}$ Department of Family \& Community Medicine, University of Toronto, Toronto, Canada

${ }^{5}$ Institute of Public Health, University of Cambridge School of Clinical Medicine, Cambridge, UK

Correspondence to

Dr SunFang Jiang; sfjiang999@ 163.com

\section{ABSTRACT}

Objectives This study aimed to examine the education and training background of Chinese community health centres (CHCs) staff, continuous medical education (CME) and factors affecting participation in CME.

Design Cross-sectional survey.

Setting Community health centres (CHCs).

Participants All doctors and nurses working in selected CHCs (excluding those solely practising traditional Chinese Medicine).

Main outcome measures CME recorded by CHCs and self-reported CME participation.

Methods A stratified random sample of CHCs based on geographical distribution and 2:1 urban-suburban ratio was selected covering three major regions of China. Two questionnaires, one for lead clinicians and another for frontline health professionals, were administered between September-December 2015, covering the demographics of clinic staff, staff training and CME activities.

Results 149 lead clinicians (response rate 79\%) and 1734 doctors and 1846 nurses completed the survey (response rate $86 \%$ ). Of the doctors, $54.5 \%$ had a bachelor degree and only $47 \%$ were registered as general practitioners (GPs). Among the doctors, $10.5 \%$ carried senior titles. Few nurses $(4.6 \%)$ had training in primary care. Those who have reported participating in CME were $91.6 \%$ doctors and $89.2 \%$ nurses. CME participation in doctors was more commonly reported by older doctors, females, those who were registered as a GP and those with intermediate or senior job titles. CME participation in nurses was more common among those with a bachelor degree or intermediate/senior job titles or those with longer working experience in the $\mathrm{CHC}$.

Conclusion Only half of doctors have bachelor degrees or are registered as GPs as their prime registration in the primary care workforce in China. The vast majority of CHC staff participated in CME but there is room for improvement in how CME is organised.

\section{INTRODUCTION}

The importance of a strong primary care system based on first contact access and provision of person-focused comprehensive care with continuity and coordination is widely accepted..$^{1-6}$ Despite a strong primary

\section{Strengths and limitations}

- We surveyed the continuous medical education (CME) situation of a random sample of 3580 medical staff in community health centres (CHCs) in mainland China, focusing on doctors and nurses, who are the core of the primary care workforce.

- Our study provides a useful baseline of the frequency and types of locally organised CME activities across a large number of CHCs.

- The main limitation of this study was that we focused on CME activities that were organised by CHCs.

- We did not evaluate the quality of CME being delivered nor whether observable health improvements had resulted from CME participation.

- Social desirability may be a source of bias especially if participation in the survey was encouraged by the supervisors.

care system being repeatedly shown to be an effective approach at reducing health inequity and achieving universal health coverage, ${ }^{2}$ many countries have yet to develop a robust primary healthcare system. Instead, primary care services are often characterised by inadequate resources and facilities, lack of appropriate training for their medical staff, variable quality in delivery of care and fragmented care. ${ }^{7}$ In China, these problems were further compounded by economic and healthcare reforms in the 1980s which involved fiscal decentralisation, commercialisation of medical services and underfunding of the public healthcare sector. These turned a generation of health professionals and the general public to rely heavily on high-tech diagnostics, expensive drugs and specialist procedures. ${ }^{8} 9$ These factors reinforced unrealistic patient expectations focused on specialist diagnostic aids and procedures, while alienating cost-efficient primary care that would better suit the nation's health needs. ${ }^{10}$ 
In 2009, the Chinese government responded to these problems and committed themselves to re-establishing primary healthcare. ${ }^{11}$ According to Health and Family Planning Commission, expenditure on primary care has reached US $\$ 17.74$ billion (US $\$ 1=¥ 6.20$ ) and accounted for approximately $30 \%$ of the public spending on health in 2014. ${ }^{12}$ In fewer than 10 years, the Chinese government has succeeded in establishing a primary care infrastructure composed mainly of rural township centres, village clinics and community health centres (CHCs) in cities. By 2014, 8669 CHCs were established, employing over 300000 health professionals, the great majority of which were from the established rural practices. However, the historical image of 'barefoot doctors' who had worked in rural regions since the $1950 \mathrm{~s}$, criticism of the healthcare system by end-users and negative publicity by the media have all led to a breakdown of trust between patients and health professionals, including in the newly revamped primary care system. ${ }^{9}$ This problem appears particularly pronounced in the cities where patients have greater choice and easier access to hospitals. One of the major problem is that CHC health professionals (doctors and nurses included) are regarded as poorly qualified and trained, and CHCs are poorly resourced, providing 'low-tech' facilities. ${ }^{13}$

In the past, medical courses were offered by a variety of colleges, vocational training schools and universities, ranging from 2 to 8 years of training. Graduates of these courses would have to sit and pass board examinations to be registered for their chosen specialties. Although shorter courses are still available to train the rural workforce, 5-year undergraduate programmes based at the university are now the norm to enter into vocational training. Nonetheless, general practice is a relatively new clinical discipline in China and there are currently few general practice departments in medical schools. ${ }^{14}$ Hence, the exposure to general practice and primary care teaching at the undergraduate level is minimal and the discipline has a low status among other clinical disciplines.

At the vocational training level, the emphasis has been on implementing the new policy of establishing primary care in a very short time span through reorientation of specialists to general practice, initially by 'on-the-job training' and later replaced by 'job-transfer training'. 'Job-transfer training' is a 1-year-long programme aimed at the less qualified doctors currently working at CHCs or those who have not undergone 'on-the-job training' which entailed a series of short courses to enhance their theoretical knowledge of general practice and practical clinical skills through a combination of lectures, hospital rotations and community-based placements. Since 2011, this has been replaced by a 3-year structured programme with 2.5 years in hospital rotations followed by 6 months in the community.

Continuous medical education (CME) aimed at maintaining, developing and enhancing medical providers' professional knowledge, skills and interpersonal capacity to keep abreast of professional lives is an essential element to maintain quality of care in this new system ${ }^{15} 16$ and CME is compulsory for ongoing registration in China. These CHC staff are required to participate in CME organised by training institutions at national, provincial, municipal, district and centre level, and they have to fulfil at least 25 credits of approved CME every year which is accredited every 2 years. According to the 'Twelfth 5 year plan, ${ }^{17} 100 \%$ of senior, $95 \%$ of midgrade and $80 \%$ of junior health professionals at provincial and city levels should achieve the required CME targets over 2 years. For staff working in western and peripheral regions of China, these targets were reduced to $95 \%, 80 \%$ and $70 \%$, respectively to reflect the phased development of primary care in these large and dispersed regions of the country. The hierarchy of the titles can only be achieved after passing the qualifying examination and fulfilling a number of stringent criteria including CME requirements, written examinations and publication of research manuscripts. This study aimed to evaluate the current organisation and manpower of CHCs in China, as well as the training (especially the content and delivery of CME) of health professionals within primary care in China.

\section{METHODS}

A nationwide survey using a stratified randomised sample was conducted among CHC medical professionals between September and December 2015. China was divided into three administrative regions: central, eastern and western. These regional differentiation are based on geographical, economical and medical jurisdiction. Two provinces were randomly selected from each region; and from these, the capital city and two-district level cities were selected at random. In addition, two of the four major municipalities (Beijing, Shanghai, Chongqing and Tianjin) were also selected at random and included in the sample. In total, 20 cities were chosen from the provinces and municipalities combined. From these, nine CHCs were randomly selected from each city (with an urbanto-suburban ratio of 2:1), giving a total of 180 CHCs. The lead clinicians and all doctors and nurses (excluding traditional Chinese herbalists) with direct patient contact from these selected CHCs were invited to participate in the survey.

The local chairpersons of the General Practitioner Associations of the six selected provinces and two selected municipalities were contacted, whom in turn, contacted the randomly selected CHCs. Training on how to distribute and complete the survey questionnaire was arranged for the coordinators of each province or municipality prior to the study. These coordinators were responsible for tracking and collecting the questionnaires. Collected data were entered and cleaned using EPIDATA V.3.1. A data entry team was responsible for data input and appointed personnel for auditing and quality control.

The study consisted of two questionnaires, one for the lead clinicians and another for CHC staff (ie, doctors 
and nurses). The former (see online supplementary file 1) covered current clinical setup, range of services and staff composition, community characteristics and patient demographics, as well as information on CME organised at the clinic. In this survey, we asked the lead clinician to use their own records to estimate the median population size of the catchment area and number of patient contacts in the past year. In the second survey, we asked the frontline health professionals about their training experience, CME participation and their willingness to conduct certain testing services. CME organised by CHCs was compared with actual participation reported by the CHC staff. These surveys were pilot tested twice on 3 CHCs and 25 practitioners with modifications made accordingly. Detailed methodology and,availability and use of primary care facilities is reported elsewhere. ${ }^{18}$

Descriptive analyses were conducted for percentages and frequencies of key parameters. These were compared with the National Health Statistics Yearbook. ${ }^{12}$ CI for the sample proportions were calculated using the Agresti-Coull (adjusted Wald) method. CME content were defined as 'clinical guidelines discussion' (ie, discussion of new clinical guidelines, ie, procedures in diagnosis or new drugs in managing a patient with a selected condition common to primary care), 'management updates' (ie, new drugs or procedures that become available to the CHC or changes in workflow at the practice) and 'case discussion' (ie, presentation of a difficult case for group input with supporting evidence from the literature). CME participation and content were broken down according to the three administrative districts which have different requirements for CME participation. Univariate logistic regression was used to explore the staff characteristics as the independent factors (with crude OR and 95\% CI calculated) associated with participation of CME by the health professionals after adjusting for gender, medical specialty, years working in the CHC, job title and education level. We also examined factors related to the clinical setup, range of services offered, staff composition, community characteristics and patient demographics (see online supplementary file 1 for full list of variables from questionnaire) and present in the paper factors which were statistically significant. All variables with $p$ values $<0.10$ was included in the multivariate model and through backward elimination, we report the final variables (with adjusted ORs (AOR)) with a p value less than 0.05 as statistically significant by convention. We adjusted the final model for age, gender, medical specialty, years working in the CHC, job title and education level. Data were analysed using STATA V.13 (StataCorp).

\section{RESULTS}

One hundred and forty-nine out of the 189 CHCs contacted provided data on their CHC (79\% response rate). Figure 1 shows the distribution of CHCs surveyed in China. The median number of full-time general practitioners working at CHC was 8 (IQR 4-14) and full-time nurses was 13 (IQR 8-12). Of the 4146 health professionals invited, 1734 doctors and 1846 nurses completed the survey giving a response rate of $86 \%$. A very small percentage of them might have double qualifications in medicine and nursing.

The median population size of the catchment area of each CHC was 50000 people (IQR 30000 to 96000 ) with a migrant population of 11100 (IQR 5000-30 000). The median patient contacts per year was 41100 (IQR 12000 to 163600). Table 1 provides the demographics of CHC staff compared with the 2015 National Health Statistics Yearbook.12 The median age of CHC doctors and nurses were young at 38 and 31 years of age, respectively, with a nurse:doctor ratio of 1.6. Women accounted for $61 \%$ of the doctors and nearly all the nurses. About half (54.5\%) of the doctors had bachelor degrees or above, yet only $10.5 \%$ of them had acquired senior titles. Despite the fact that all were practising as general practitioners (GPs), only $47 \%$ were actually registered as one. Doctors and nurses had worked for a median of 14 years and 9 years, respectively.

Table 2 shows the range and frequency of reported on-site CME and CME participation at each CHC. CME activities were held by nearly all CHCs $(97.2 \%)$, where about two-thirds (67.1\%) conducted CME sessions monthly or more frequently. The type of in-house CME activities reported were clinical guidelines discussion $(100 \%)$, management updates $(87.9 \%)$ and case discussions $(83.6 \%)$.

Table 3 shows CME participation for different types of health professionals in the three administrative districts. Despite CME participation being extremely high (ranging between $86 \%$ to $100 \%$ ), those in the central and eastern regions fell short of the targets set by the State. In contrast to what was expected by the government, there was no significant difference of CME participation by GPs in the three administrative regions, and CME participation was actually more common among junior doctors in the western and peripheral regions compared with the central and eastern regions $(\mathrm{p}=0.036)$.

Table 4 summarises the multivariate analysis of health professionals' characteristics with CME participation. Among doctors, CME participation was more common among older doctors (adjusted ORs (aOR) 1.04 per year), women (aOR 1.7), those registered as GPs (aOR 3.0) and those with an intermediate or senior job title (aOR 2.2). Among nurses, CME participation was more common among those with bachelor degrees (aOR 2.9), with longer experience working in general practice (aOR 1.1 per year) or with an intermediate or senior job title (aOR 2.2).

\section{DISCUSSION}

This large study of China's CHCs examines the current primary care workforce and finds it is predominantly staffed by young female health professionals, with only half of doctors holding a bachelor degree or higher or 


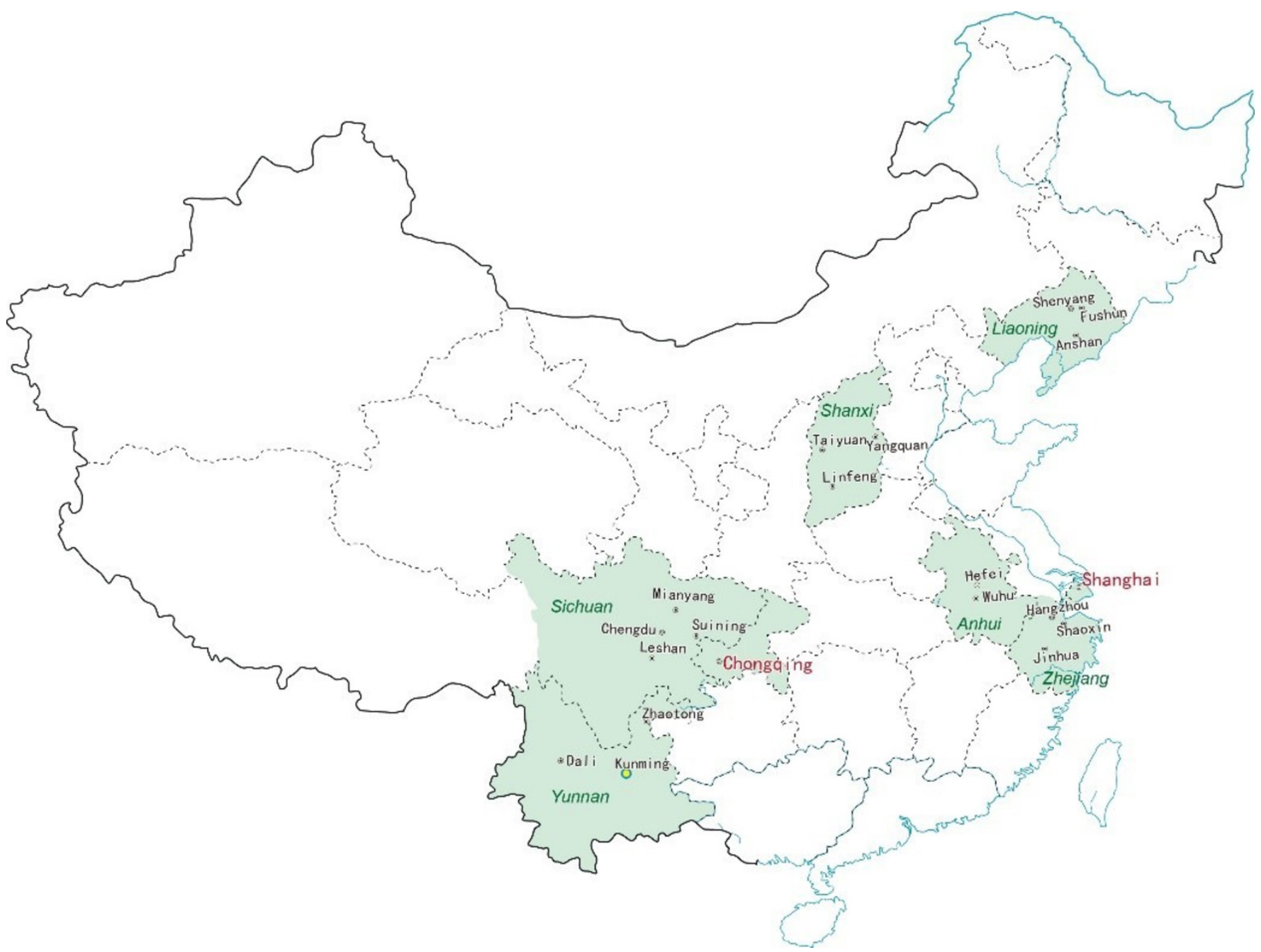

Figure 1 Geographical distribution of the selected cities that participated in the survey.

registered as a GP. The relatively low nurse:doctor ratio may reflect the focus of care on doctor-centred approach in the traditional medical model. Indeed, the lead physicians reported on average there were 1-2 pharmacists, physiotherapists, laboratory technicians or radiographers but clinical psychologists or medical social workers were uncommon. The ratio was far from the international standard of approximately three nurses per doctors as recommended by WHO.$^{19}$ Evidence exists that an undersupply of nurses could result in inefficient allocation of resources. ${ }^{20}$

For historical reasons, many practising health professionals at CHCs do not have a bachelor degree. ${ }^{14}$ Indeed, our study shows just over half of the doctors and under a third of the nurses working in primary care have a bachelor degree. This may contribute in part to the perception of poor training and poor quality in primary care. The quality of healthcare should be based on the quality of the workforce rather than just increasing the sheer quantity of staff as it has been the focus of China's policy on development of primary care thus far. The education level and title seniority through examination are considered important indicators of professional standards and competency. Nurses who have a higher level of education provide better healthcare and safety for their patients. ${ }^{21}$

In China, due to the short history of primary care development, many senior doctors were previously either public health physicians or specialist who converted to being GPs and were given the task of setting up CHCs. Previously 'on-the-job' and now 'job-transfer' training is offered to the specialists who have converted to work as GPs before sitting the qualifying examination. To attract them to primary care, they are allowed to keep up to three specialties on their registration but in our survey, only $47 \%$ of the doctors chose to register general practice as their prime registration. We confirm that the CME participation rates for those registered as GPs are higher than those still registered as a specialist. Further, 97\% of staff members with intermediate and senior level job titles participated in CME, which accounted for 39\% of all CHC health professionals (52\% of GPs and $29 \%$ of nurses). An advancement in job titles may provide a sense of ownership and autonomy, ${ }^{9}$ and thus was identified as an independent factor in the participation of CME in our study. 
Table 1 Basic characteristics and training of CHC health professionals, compared with the 2015 National Health Statistics Yearbook $^{12}$

\begin{tabular}{|c|c|c|c|c|c|c|}
\hline \multirow[b]{2}{*}{ Variables } & \multicolumn{2}{|l|}{ Doctors } & \multirow[t]{2}{*}{$\begin{array}{l}2015 \\
\text { Yearbook }\end{array}$} & \multicolumn{2}{|l|}{ Nurses } & \multirow[t]{2}{*}{$\begin{array}{l}2015 \\
\text { Yearbook }\end{array}$} \\
\hline & $\mathrm{n} / \mathrm{N}$ & $\%(95 \% \mathrm{Cl})$ & & $n / N$ & $\%(95 \% \mathrm{Cl})$ & \\
\hline Median Age (IQR) & & 38 (32 to 46$)$ & - & & 31 (26 to 39$)$ & - \\
\hline \multicolumn{7}{|l|}{ Gender } \\
\hline Female & $1025 / 1675$ & $\begin{array}{l}61.2 \\
(58.8 \text { to } 63.5)\end{array}$ & 53.2 & $1,793 / 1803$ & $\begin{array}{l}99.4 \\
(99.0 \text { to } 99.7)\end{array}$ & 99.4 \\
\hline \multicolumn{7}{|l|}{ Education } \\
\hline Below associate degree & $202 / 1724$ & $\begin{array}{l}11.7 \\
(10.2 \text { to } 13.3)\end{array}$ & 19.1 & $382 / 1831$ & $\begin{array}{l}20.9 \\
(19.0 \text { to } 22.8)\end{array}$ & 44.4 \\
\hline Associate degree ${ }^{\star}$ & $582 / 1724$ & $\begin{array}{l}33.8 \\
(31.5 \text { to } 36.0)\end{array}$ & 36.9 & $920 / 1831$ & $\begin{array}{l}50.2 \\
(47.9 \text { to } 52.6)\end{array}$ & 48.3 \\
\hline Bachelor degree or higher & $940 / 1724$ & $\begin{array}{l}54.5 \\
(52.1 \text { to } 56.9)\end{array}$ & 44.0 & $529 / 1831$ & $\begin{array}{l}28.9 \\
(26.8 \text { to } 31.0)\end{array}$ & 10.3 \\
\hline \multicolumn{7}{|l|}{ Job title } \\
\hline Senior & $180 / 1711$ & $\begin{array}{l}10.5 \\
(9.1 \text { to } 12.1)\end{array}$ & 10.5 & $46 / 1815$ & $\begin{array}{l}2.5 \\
(1.9 \text { to } 3.4)\end{array}$ & 1.5 \\
\hline Intermediate & $705 / 1711$ & $\begin{array}{l}41.2 \\
\text { (38.9 to } 43.6)\end{array}$ & 41.3 & $471 / 1815$ & $\begin{array}{l}26.0 \\
(23.9 \text { to } 28.0)\end{array}$ & 22.2 \\
\hline Junior & $683 / 1711$ & $\begin{array}{l}39.9 \\
(37.6 \text { to } 42.3)\end{array}$ & 41.9 & $1,158 / 1815$ & $\begin{array}{l}63.8 \\
(61.5 \text { to } 66.0)\end{array}$ & 66.9 \\
\hline None & $143 / 1711$ & $\begin{array}{l}8.4 \\
(7.1 \text { to } 9.8)\end{array}$ & 6.2 & $140 / 1815$ & $\begin{array}{l}7.7 \\
(6.5 \text { to } 9.0)\end{array}$ & 9.4 \\
\hline \multicolumn{7}{|l|}{ Registered specialty } \\
\hline Integrative medicine & $145 / 1700$ & $\begin{array}{l}8.5 \\
(7.2 \text { to } 10.0)\end{array}$ & - & $2 / 1834$ & $\begin{array}{l}0.1 \\
(0.0 \text { to } 0.4)\end{array}$ & - \\
\hline General practice & $799 / 1700$ & $\begin{array}{l}47.0 \\
(44.6 \text { to } 49.4)\end{array}$ & - & $85 / 1834$ & $\begin{array}{l}4.6 \\
(3.7 \text { to } 5.7)\end{array}$ & - \\
\hline Other specialty & $454 / 1700$ & $\begin{array}{l}26.7 \\
(24.6 \text { to } 28.9)\end{array}$ & - & $19 / 1834$ & $\begin{array}{l}1.0 \\
(0.6 \text { to } 1.6)\end{array}$ & - \\
\hline Nurse & $23 / 1700$ & $\begin{array}{l}1.4 \\
\text { (0.9 to } 2.0)\end{array}$ & - & $1712 / 1834$ & $\begin{array}{l}93.3 \\
\text { (92.1 to } 94.4)\end{array}$ & - \\
\hline None & $75 / 1700$ & $\begin{array}{l}4.4 \\
(3.5 \text { to } 5.5)\end{array}$ & - & $30 / 1834$ & $\begin{array}{l}1.6 \\
\text { (1.1 to } 2.3)\end{array}$ & - \\
\hline Other & $295 / 1700$ & $\begin{array}{l}17.4 \\
(15.6 \text { to } 19.2)\end{array}$ & - & $18 / 1834$ & $\begin{array}{l}1.0 \\
(0.6 \text { to } 1.5)\end{array}$ & - \\
\hline $\begin{array}{l}\text { Median years working in } \\
\text { above specialty (IQR) }\end{array}$ & $14(7-23)$ & & - & $9(4-18)$ & & - \\
\hline
\end{tabular}

${ }^{*}$ Associate degree refers to 2 years health-related subdegree equivalent to a physician assistant.

$\mathrm{CHC}$, community health centre.

CME is a requirement for practising professionals in many countries including China to maintain medical knowledge and skills. ${ }^{22}$ Doctors who do not participate in CME have lower confidence when making clinical decisions. ${ }^{21}$ Although it is encouraging to see nearly all CHC staff had participated in CME, one-third of CHCs organise on-site CME activities once every quarter or even once a year, which is far from satisfactory. A Cochrane review suggests that CME should be accessible within health professionals' own clinical communities. ${ }^{23}$ Other forms of CME might include attending professional conferences, research workshops or distance learning courses as long as they have been approved by the postgraduate centre in their respective city, but the focus of CME undergone by doctors or nurses could be different and there are no fixed rules as how frequent they should attend these activities. Learning objectives must be tailored beyond meeting the staff's CME requirements where each CHC or jointly in a locality should take into account the local context and needs for example, the local disease pattern and epidemiology, and to provide the necessary training and support to their staff to address the skill mix to deliver the service. 
Table 2 Continuous medical education organised and undertaken by the CHCs

\begin{tabular}{|c|c|c|}
\hline & $\mathrm{n} / \mathrm{N}$ & $\%(95 \% \mathrm{Cl})$ \\
\hline $\mathrm{CHC}$ offering $\mathrm{CME}$ & $140 / 144$ & 97.2 (93.0 to 99.2$)$ \\
\hline \multicolumn{3}{|c|}{ Frequency of $\mathrm{CME}$ organised at $\mathrm{CHCs}$} \\
\hline Yearly & $16 / 140$ & $11.4(7.1$ to 17.9$)$ \\
\hline Quarterly & $25 / 140$ & 17.9 (12.3 to 25.1$)$ \\
\hline Bimonthly & $13 / 140$ & $9.3(5.4$ to 15.4$)$ \\
\hline Monthly & $77 / 140$ & 55.0 (46.7 to 63.0$)$ \\
\hline Biweekly & $15 / 140$ & $10.7(6.5$ to 17.0$)$ \\
\hline Weekly & $2 / 140$ & $1.4(0.1$ to 5.4$)$ \\
\hline \multicolumn{3}{|l|}{ Staff participating in CME } \\
\hline Managers & $140 / 140$ & 100 (96.8 to 100$)$ \\
\hline Doctors & $140 / 140$ & 100.0 (96.8 to 100.0$)$ \\
\hline Nurses & $140 / 140$ & 100.0 (96.8 to 100.0$)$ \\
\hline Other medical staff & $126 / 140$ & $90.0(83.8$ to 94.1$)$ \\
\hline \multicolumn{3}{|l|}{ Types of CME activities } \\
\hline Clinical guideline discussion & $140 / 140$ & 100 (96.8 to 100$)$ \\
\hline Management updates & $123 / 140$ & $87.9(81.3$ to 92.4$)$ \\
\hline Case discussions & $117 / 140$ & 83.6 (76.5 to 88.9$)$ \\
\hline
\end{tabular}

$\mathrm{CHCs}$, community health centres; $\mathrm{CME}$, continuous medical education.

Arguably, reflective learning, meeting self-defined learning objectives and auditing clinical performance with practitioners expected to demonstrate certain competencies in managing the patients independently would be more appropriate in quality improvement rather than time-based training. ${ }^{21}$ Lack of time and appropriate resources have been reported as obstacles for CME participation in China. ${ }^{24}$ Alternatives such as self-directed searches in the medical literature or medical websites, or structured resources on the internet (eg, BMJ learning) or medical journals, exist to meet their learning needs. ${ }^{25}{ }^{26}$ Nonetheless, these alternatives are limited by the motivation and skills required to perform these searches effectively as well as the availability and accessibility (including the language barrier) of these resources.

Our study suggests that $97.2 \%$ of CHCs hold discussions and learning sessions about treatment protocols and $84.8 \%$ on disease updates. If used well, evidencebased medicine can aid health professionals in making the most appropriate therapeutic decisions for individual patients and conditions at the clinical level. However, rapid advancements in therapeutic methods and multiple guidelines from both local and international agencies have made it difficult for health professionals to follow them closely. Primary healthcare staff can learn and incorporate these new updates and guidelines into their clinical practices only when they engage in the dissemination and implementation at the early stage and have the support of their senior colleagues. Moreover, GPs need to take the opportunities provided by CME to share difficulties when dealing with individual patients and build the team to cope with different professional environments. ${ }^{27}$
Significant event audit is a regular and compulsory part of annual appraisal for all doctors in the NHS in the UK. ${ }^{28}$

Our survey found that the current CME participation fell short of the overall 95\% standard from the 'Twelfth Five Years Plan', ${ }^{17}$ where $92 \%$ of doctors and $89 \%$ of nurses surveyed reported regular CME participation. Contrary to what was believed by the policy-makers (as reflected in the targets set), participation rates for doctors from the Western and peripheral region CME not only exceeded the target, but evidently Western and peripheral region doctors of junior title had participated more than their counterparts in the other regions, which suggests such regional differentiation is unnecessary.

This study should be interpreted in light of some limitations. The main limitation of this study was that we only focused on CME activities that were organised by CHCs but arguably those were the most commonly attended by the staff of individual CHCs. It would be valuable to also know how frequently staff participated in CMEs conducted outside of organisations (eg, by training institutions or self-directed learning). We did not evaluate the quality of CME being delivered nor whether observable health improvements had resulted from CME participation. Other important parameters for CME evaluation to consider would be costs to attend CME, management support, funding/resources and quality of CME instructors/coaches. Although we surveyed over 3500 medial staff from a random sample of CHCs in China, they may not be representative of all CHC staff in China. Moreover, social desirability may be a source of bias especially if participation in the survey was encouraged by the supervisors. These could be the subject of future research 


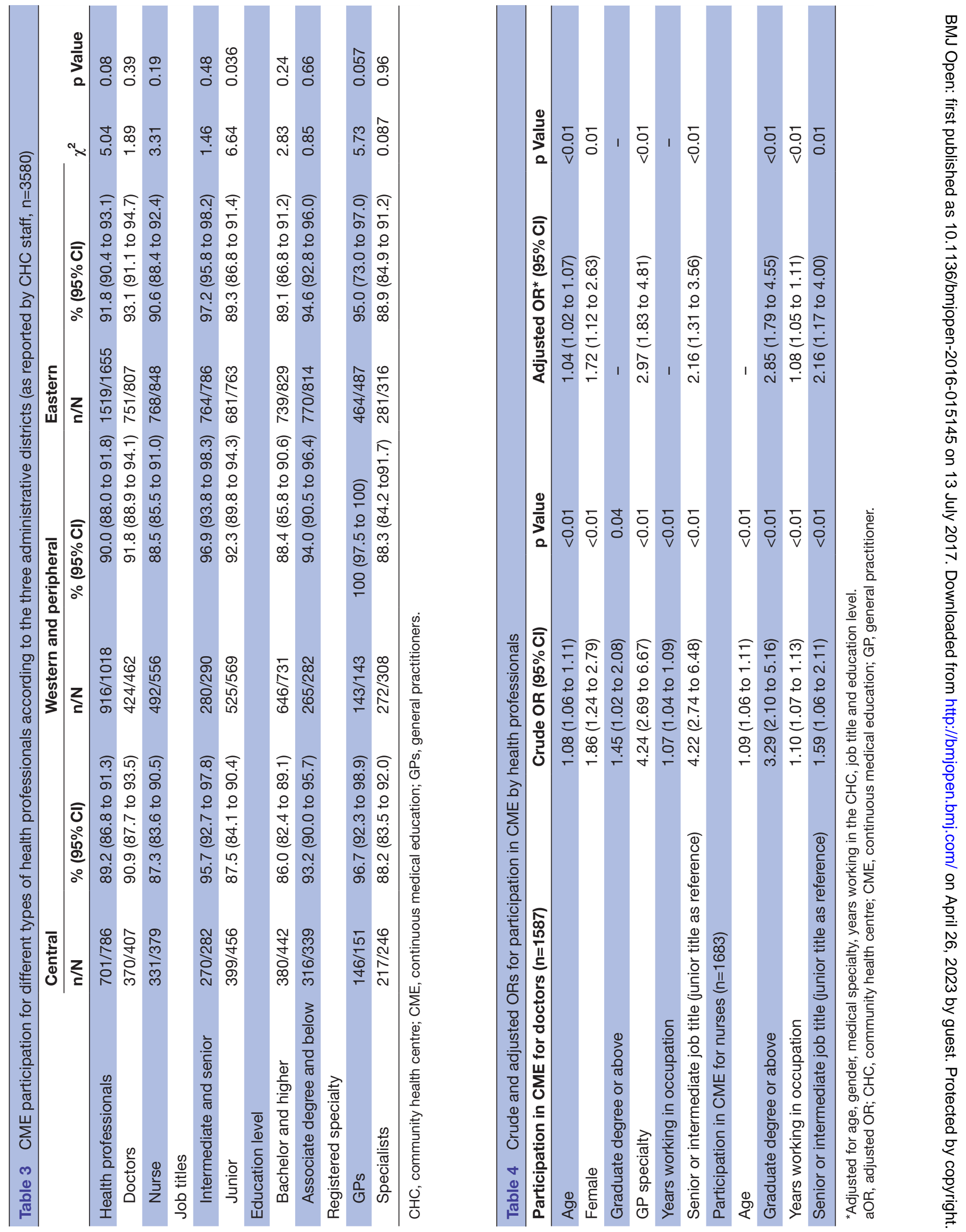


through in-depth qualitative interviews of CHC staff and focused evaluations of CME programmes in China.

\section{CONCLUSION}

In this study, it shows the high participation rates of CME among health professionals in CHCs, if used well, could maintain high standards of practice among the primary care workforce in China. CHCs could focus on improving nurses-to-doctor, bachelors-to-non-graduate and title seniority ratios as quality workforce improvements. There are disadvantages to continue to rely on conversion of specialists as a source of primary care workforce. At the same time, CME programmes should be decentralised and take on various forms to meet the local and individual needs while regional CME differentiation is unnecessary.

Acknowledgements We thank the General Practice Society of Chinese Medical Association for offering assistance to organise this study. The biggest thank is given to the experts of General Practice Society of the provinces and municipalities, including Professor Dongdong Chen (Shanghai), Professor Bo Xie (Chongqing), Professor Xiaosong Yu and Professor Shuang Wang (Liaoning), Professor Lizheng Fang (Zhejiang), Professor Mei Feng (Shanxi), Professor Guangbin Zhao (Sichuan), Professor Haiqin Tang and Professor Jing Rui (Anhui), and Professor Li He (Yunnan), who provided the communication with the $\mathrm{CHCs}$ and the investigation implementation. We also thank all the CHCs and doctors/nurses who have engaged in the survey.

Contributors WCW Wong designed the study and the questionnaire and wrote up the report. SZZ led the team and oversaw the implementation and liaised with different Chinese GP Associations. J0 conducted the data analysis and drafted the results of the manuscript with WCW. MHP implemented the study and helped some of the data analysis. CLKL, MRK and MR advised on the study design and questionnaire and commented on the reports. SFJ led the team and oversaw the implementation, led the pilot testing as well as implementation of the study, took part in the discussion and modification of the design and the questionnaire.

Funding This project is supported by three funding sources: RGC Seed fund for basic research, University Grant Council, HK SAR Government, entitled, Survey of the Attitudes and Needs of Integrated HIV and STI Services in Community Health Centres in China (2015-16) (project no. 201411159004); Shanghai Key Discipline Construction Program in Public Health (Shanghai Municipal Commission of Health and Family Planning, project no. 12GWZX1001) and Shanghai Excellent Academic Leaders Training Program in Public Health (Shanghai Municipal Commission of Health and Family Planning, project no. GWDTR201210).

\section{Competing interests None declared.}

Ethics approval Ethics committee approvals from a local board (HKU/HAW IRB: UW15-350) and the WHO Regional Office for the Western Pacific: (2016.4.CHN.1.HSI) were obtained.

Provenance and peer review Not commissioned; externally peer reviewed. Data sharing statement No additional data are available.

Open Access This is an Open Access article distributed in accordance with the Creative Commons Attribution Non Commercial (CC BY-NC 4.0) license, which permits others to distribute, remix, adapt, build upon this work non-commercially, and license their derivative works on different terms, provided the original work is properly cited and the use is non-commercial. See: http://creativecommons.org/ licenses/by-nc/4.0/

C Article author(s) (or their employer(s) unless otherwise stated in the text of the article) 2017. All rights reserved. No commercial use is permitted unless otherwise expressly granted.

\section{REFERENCE}

1. Fendall NRE. Declaration of Alma-ATA. The Lancet 1978;312:1308.
2. Starfield B, Shi L, Macinko J. Contribution of primary care to health systems and health. Milbank Q 2005;83:457-502.

3. Kringos D, Boerma W, Bourgueil $\mathrm{Y}$, et al. The strength of primary care in Europe: an international comparative study. $\mathrm{Br} J$ Gen Pract 2013;63:742-50.

4. Pelone F, Kringos DS, Spreeuwenberg P, et al. How to achieve optimal organization of primary care service delivery at system level: lessons from Europe. Int J Qual Health Care 2013;25:381-93.

5. Doubova SV, Guanais FC, Pérez-Cuevas R, et al. Attributes of patient-centered primary care associated with the public perception of good healthcare quality in Brazil, Colombia, Mexico and El Salvador. Health Policy Plan 2016;31:834-43.

6. Hall JJ, Taylor R. Health for all beyond 2000: the demise of the AlmaAta Declaration and primary health care in developing countries. Med $J$ Aust 2003;178:17-20.

7. Organization WH. The World Health Report 2008: primary health care (now more than ever), 2014

8. Yao S, Zeng Q, Peng M, et al. Stop violence against medical workers in China. $J$ Thorac Dis 2014;6:E141.

9. Wagstaff A. Reforming China's rural health system: World Bank Publications, 2009

10. Tucker JD, Cheng Y, Wong B, et al.Patient-physician mistrust and violence against physicians in Guangdong Province, China: a qualitative study. BMJ Open 2015;5:e008221.

11. Chen Z. Launch of the health-care reform plan in China. The Lancet 2009;373:1322-4.

12. Commission NHaFP. China Health and Family Planning Statistics Yearbook. Beijing, China, 2015

13. Zhao $\mathrm{Y}$, Chen R, Wang B, et al. General practice on-the-job training in Chinese urban community: a qualitative study on needs and challenges. PLoS One 2014;9:e94301.

14. Mash R, Almeida M, Wong WC, et al. The roles and training of primary care doctors: China, India, Brazil and South Africa. Hum Resour Health 2015;13:1-9.

15. Shumway JM, Harden RM.AMEE Guide No. 25: The assessment of learning outcomes for the competent and reflective physician. Med Teach 2003;25:569-84.

16. Brown JA, Beaser RS, Neighbours J, et al. The integrated Joslin performance improvement/CME program: a new paradigm for better diabetes care. J Contin Educ Health Prof 2011;31:57-63.

17. Health and Family Planning Commission. The guideline of strengthening cuntinuing medical education during the "twelve-fiveyear". http://www.nhfpc.gov.cn/zwgkzt/pghjh/201301/92ca88ac eeab4ea098f3519d22972d94.shtml

18. Wong WCW, Jiang S, Ong JJ, et al. Bridging the Gaps between patients and primary care in China: a nationwide representative survey. Ann Fam Med 2017;15:237-45.

19. Ghaffar A, Kazi BM, Salma M. Health care systems in transition III. Pakistan, part 1. An overview of the healthcare system in Pakistan. Pub Health Med 2000;22:38-42.

20. Goryakin Y, Griffiths P, Maben J. Economic evaluation of nurse staffing and nurse substitution in health care: a scoping review. Int $J$ Nurs Stud 2011:48:501-12.

21. Aiken LH, Clarke SP, Cheung RB, et al. Educational levels of hospital nurses and surgical patient mortality. JAMA 2003;290:1617-23.

22. Tang JZ, Ma X. Implication of the continuing medical education mode in western countries. : Northwest Medical Education, 2010:18: 933-7.

23. Grobler L, Marais BJ, Mabunda S. Interventions for increasing the proportion of health professionals practising in rural and other underserved areas. Cochrane Database Syst Rev 2015;6:CD005314.

24. Wang G, Sq H, Chen YW, et al. Investigation on current situation of continuing medical education in hospital at prefecture level in the minority area of Yunnan province and reflection on its strategies. Chin J of Med Edu Res 2012;11:437-40.

25. Ebell MH, Cervero R, Joaquin E. Questions asked by physicians as the basis for continuing education needs assessment. J Contin Educ Health Prof 2011;31:3-14.

26. McKeithen T, Robertson S, Speight M. Developing clinical competencies to assess learning needs and outcomes: the experience of the CS2day initiative. J Contin Educ Health Prof 2011;31(Suppl 1):S21-S27.

27. Zarif Sanaiey N, Karamnejad S, Rezaee R. Educational needs of family physicians in the domains of health and conformity with continuing education in Fasa University of Medical Sciences. J Adv Med Educ Prof 2015;3:84-9.

28. RCGP. Significant event audit. http://www.rcgp.org.uk/clinical-andresearch/our-programmes/quality-improvement/significant-eventaudit.aspx 